Second United Nations

International Conference

on the Peaceful Uses of

Atomic Energy
$\mathrm{A} / \mathrm{CONF} \cdot 15 / \mathrm{P} / 690$

U.S.A.

June 1958

ORIGINAL: ENGLISH

\title{
AN EXPERIMENT AL STUDY OF FISSION IN THE ACTINIDE ELEMENTS
}

A. Smith, P. Fields, A. Friedman, S. Cox and R. Sjoblom*

\section{INTRODUCTION,}

The atomic nucleus is characterized by a charge $\mathrm{Z}$ and mass $A$. Until recently all fissionable nuclei possessed nearly the same charge and mass. As a result the characteristics of the known fission processes were similar. During the past several years many new fissile isotopes have become available in sufficient quantities to permit study of their properties. As a group they display a wide variation in their fission characteristics; some of them fission spontaneously. It is the purpose of the experiments reported here to utilize these new isotopes to obtain a clearer experimental insight into the mechanism of fission and to obtain information that will lead to new and better applications of the fission phenomena. This group of experiments consists of: determinations of fission fragment kinetic energy distributions, measurements of fission neutron spectra, a study of prompt fission gamma ray emission, and an investigation of delayed neutron emission from spontaneous fission.

\section{THE KINETICS OF FISSION FRAGMENTS}

A large portion of the energy available in fission appears as a violent kinetic motion of the massive fragments. The manner in which this energy is shared between the fragments is related, in a verycomplex way, to the structures of the fissioning nucleus and the residual fragments. A complete understanding of the fission phenomena must account for this distribution of energy. In order to expand the experimental basis for theoretical interpretation of the fission process a study has been made of the kinetic distribution of fragments from the fission of $\mathrm{Pu}^{240} \# *, \mathrm{Pu}^{242} \# *, \mathrm{Th}^{230} \#, \mathrm{Cm}^{244}, \mathrm{Cm}^{242 *}, \mathrm{Cf}^{252 *}$ and $\mathrm{Fm}^{254 *}$ !

The kinetic energy of each of the two primary fission fragments was measured simultaneously in a back-to-back ionization chamber. (1) Most of

* Argonne National Laboratory, Lemont, Illinois, U.S.A.

TThroughout this paper we refer to the mass number of the actual fissioning is otope. The symbols \# and * are used to denote slow neutron induced and spontaneous fission processes respectively. 


\section{DISCLAIMER}

This report was prepared as an account of work sponsored by an agency of the United States Government. Neither the United States Government nor any agency Thereof, nor any of their employees, makes any warranty, express or implied, or assumes any legal liability or responsibility for the accuracy, completeness, or usefulness of any information, apparatus, product, or process disclosed, or represents that its use would not infringe privately owned rights. Reference herein to any specific commercial product, process, or service by trade name, trademark, manufacturer, or otherwise does not necessarily constitute or imply its endorsement, recommendation, or favoring by the United States Government or any agency thereof. The views and opinions of authors expressed herein do not necessarily state or reflect those of the United States Government or any agency thereof. 


\section{DISCLAIMER}

Portions of this document may be illegible in electronic image products. Images are produced from the best available original document. 
the fissionable material was obtained from $\mathrm{Pu}^{239}$ that had been irradiated in a high flux reactor. Chemical processing assured that the effective purity of the material was at least $95 \%$.(2) The sample itself was prepared by vacuum volatilization, chloride sublimation or by electrostatic deposition depending on the nature of the material involved.

The experimental results are summarized in Table $I$, along with the results of kinetic measurements and chemical yield determinations by other workers. It is qualitatively evident that all slow neutron induced and spontaneous fission processes observed are asymmetric. Furthermore, these experiments show no measurable difference between the slow neutron induced and the spontaneous fission of a given nucleus. The total fragment energy is a slowly increasing function of the fission parameter $\mathrm{Z}^{2} / \mathrm{A}$ up to and including $\mathrm{Cm}^{242 *}$. At $\mathrm{Cf}^{252 *}$ the trend is reversed with decreasing total energy for higher values of $\mathrm{Z}^{2} / \mathrm{A}$. This is shown graphically in Fig. 1. In all processes studied the distribution of total fragment energy integrated over all modes was a symmetric function with a half width of $\sim 16-18 \%$. At the most probable mode the energy spread was $\sim 13 \%$. These values are in good agreement with magnetic and velocity determinations $(3,4,5)$ and indicate that the dispersion in fission fragment ionization is not as great as was once believed. The total energy at the symmetric mode is not well defined by these experiments because of the low yield. However, generally higher total energies occur as the symmetric mode is approached in agreement with theoretical predictions. $(6,7)$

Table I

SUMMARY UF FISSION FRAGMENT PROPERTIES

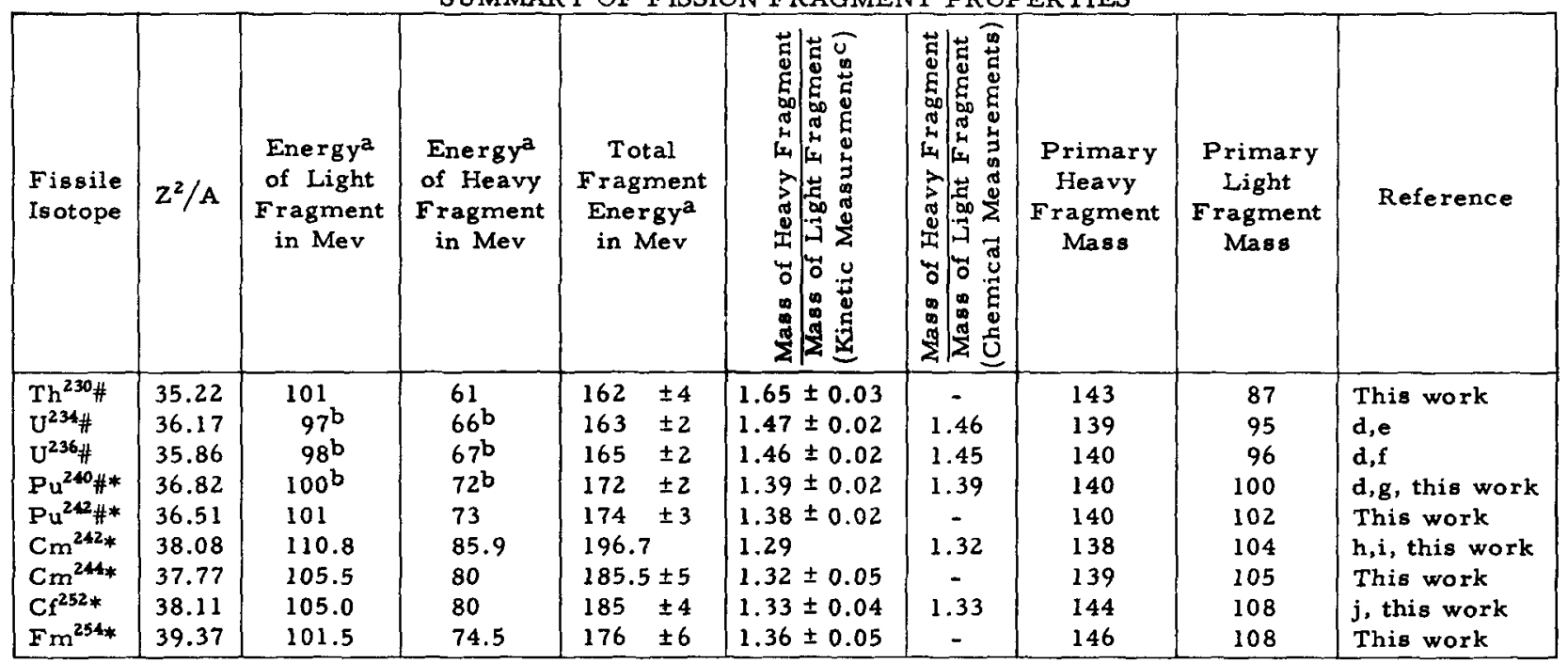

a All fonization chamber measurements corrected for the ionization defect, see reference 3 cDenotes average values. All others are most probable derimary ragment ratios

Glendenin, et a.., Phys. Rev., 95:867 (1954)

Glendenin, et al., Phys. Rev., 94:860 (1951)

SStetnberg, E. and Freedman, M., Radiochenical Studtes: The Fission ProductB, MoGraw-Hill Book Co., Inc., New Xork (1951) Paper No. 210, National Nuclear Enerwy Serles, Plutonlum Project Record, Vol. g Div. IV.

1 Stelnberc, et al., Phys. Rev., 93:431 (1954)

jolendenin, L., steinberE, E., J. Inort. und Nuclear Chem., I, $\mathbf{5}$ ( 1055) 


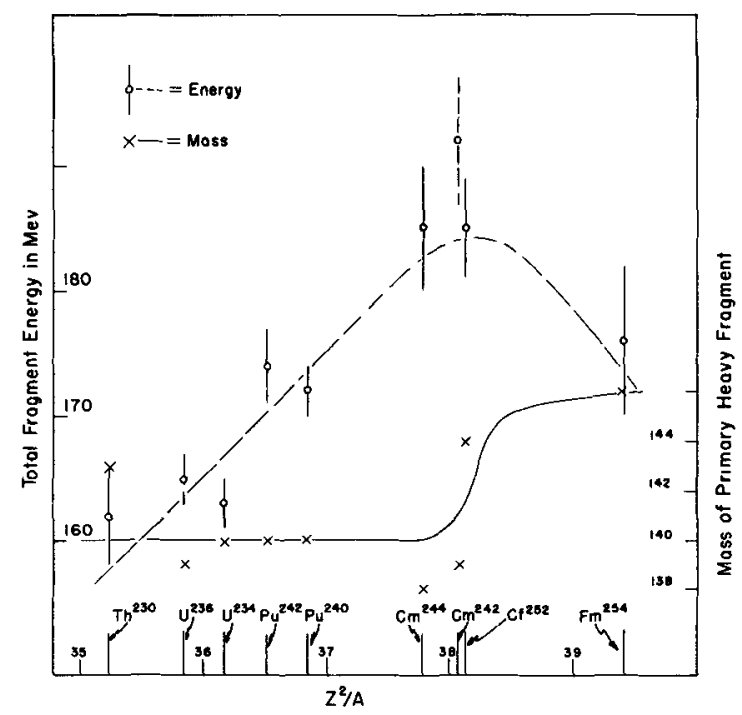

Fig. 1

A graphical summary of the results of fission fragment kinetic studies

The primary fission fragment masses as determined by kinetic measurements are given in Table $I$, and plotted as a function of the fission parameter $\mathrm{Z}^{2} / \mathrm{A}$ in Fig. 1. The heavy fragment mass is nearly constant for all fission processes. However, there is an indication that the heavy fragment mass increases for values of $\mathrm{Z}^{2} / \mathrm{A}$ greater than 38.1. This value of $\mathrm{Z}^{2} / \mathrm{A}$ corresponds to the maximum of the total energy curve. Furthermore, a discontinuity exists in the systematics of the alpha decay of heavy nuclei(8) in this same region. It may well be that all of these effects are associated with the closing of a neutron shell at neutron number 152 .

\section{THE FISSION NEUTRON SPECTRA OF $\mathrm{Pu}^{242} \#, \mathrm{U}^{234} \#$ AND $\mathrm{Cf}^{252} *$}

A knowledge of the fission neutron spectrum is requisite to the proper design of multiplying systems and is fundamental to a thorough understanding of the fission process. The fission neutron spectra of $\mathrm{U}^{236} \#$ and $\mathrm{Pu}^{240} \#$ have been experimentally studied. $(9,10)$ With the advent of the breeding reactor concept a knowledge of the neutron spectra of $\mathrm{U}^{234} \#$ and $\mathrm{Pu}^{242} \#$ is of increas ing importance. Moreover, the fission neutron spectrum gives us one of the best methods of experimentally determining the nuclear temperature of the fission fragments. In order to give a better ins ight into the fission process and to obtain useful reactor design parameters an experimental determination of the fission neutron spectra of $\mathrm{U}^{234} \#, \mathrm{Pu}^{242} \#$ and $\mathrm{Cf}^{252 *}$ was carried out.

These fission neutron spectra were measured using proton recoils in emulsions and time of flight techniques. The recoil emulsion studies covered the energy range 1.1 to $8.0 \mathrm{Mev}$ and the time of flight measurements extended from 0.3 to $3.0 \mathrm{Mev}$. C-2 Ilford emulsions were arranged about an essentially point source of fission material (see Fig. 2). This fissile sample 


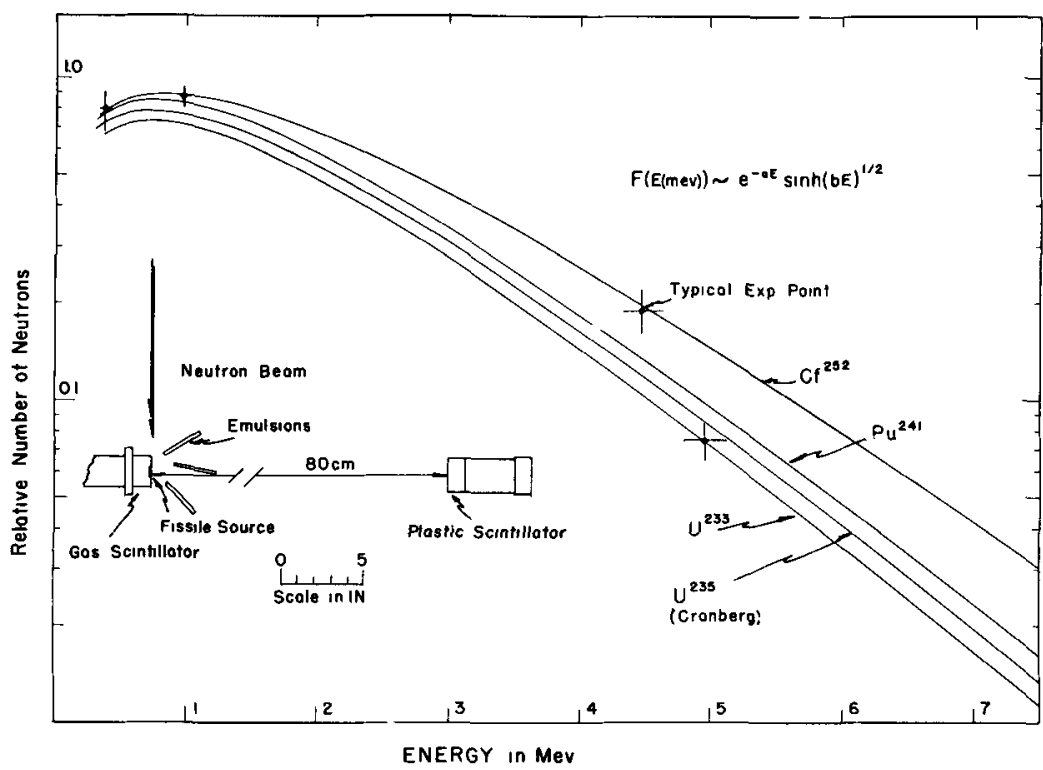

Fig. 2

A comparison of the fission neutron spectra of $\mathrm{U}^{235}+\mathrm{n}_{\mathrm{th}}$, $\mathrm{U}^{233}+\mathrm{n}_{\mathrm{th}}$. $\mathrm{Pu}^{241}+\mathrm{n}_{\text {th }}$ and $\mathrm{Cf}^{252}$ (spontaneous). The normalization of the distributions is chosen for clear representation and is otherwise arbitrary. A schematic diagram of the experimental arrangement is also shown.

was then bombarded with thermal neutrons collimated in such a manner that the fogging of the emulsions was kept to a minimum. In the case of $\mathrm{Cf}^{252 *}$ the spontaneous nature of the process made the neutron beam unnecessary. Throughout the experiments considerable care was taken to eliminate any undesired perturbation of the fission spectra being studied. The emulsions were processed and read in a conventional manner described elsewhere in these proceedings.(11)

The time of flight measurements are basically a determination of the time required for the neutrons to traverse the distance between the fission source and the neutron detector.(12) The fissionable material was contained within a gas scintillation system. This detector provided a fast time marker coincident with the fission event. The neutron detector was a plastic scintillator situated between 50 and $80 \mathrm{~cm}$ from the neutron source (see Fig. 2). In making the time measurements it was assumed that the fission neutrons were emitted within $<10^{-9} \mathrm{sec}$ of fission.(13) In addition to the above experiments, the fission neutron spectrum of $U^{236} \#$ was measured. The resulting distribution was in good agreement with that obtained by other workers. (9)

The fission neutron spectra of $\mathrm{U}^{234} \#, \mathrm{Pu}^{242} \#$ and $\mathrm{Cf}^{252 *}$ are well represented by the "Watt" empirical expression:(14)

$$
F[E(M e v)] \sim e^{-a E} \sinh (b E)^{1 / 2}
$$

where $F(E)$ is the number of neutrons per unit energy and the constants a and $\mathrm{b}$ take the values given in Table II. The table also includes the values of

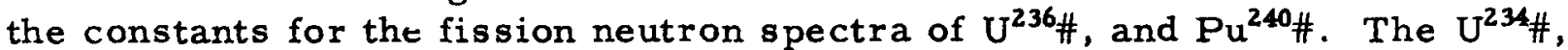
$\mathrm{Pu}^{242} \#$ and $\mathrm{Cf}^{252} *$ spectra are graphically compared with one anothe $\mathrm{r}$ and with the $\mathrm{U}^{236} \#$ spectrum in Fig. 2. From the figure and table it is evident that the 
PARAMETERS FOR THE EMPIRICAL FISSION NEUTRON SPECTRAL DISTRIBUTION

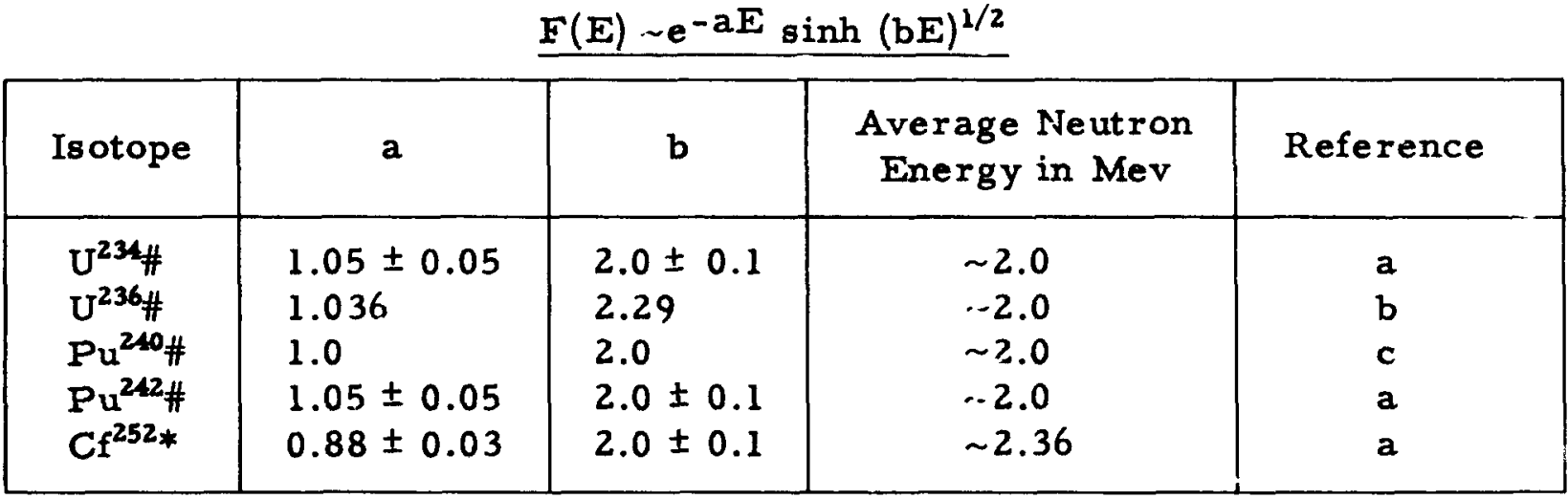

$a=$ present work $\quad b=$ see reference $9 \quad c=$ see reference 10

fission spectra of $\mathrm{U}^{234} \#, \mathrm{Pu}^{240} \#$ and $\mathrm{Pu}^{242} \#$ are, within the experimental accuracy, identical to that of $\mathrm{U}^{236} \#$ while the spectrum of $\mathrm{Cf}^{252 *}$ is noticeably more energetic.

By detailed balancing of the partition of fission energy, Leachman(16) has obtained theoretical agreement with many experimentally determined fission properties. With a fragment temperature of i.0 Mev he calculated spectra in qualitative agreement with the measured $\mathrm{U}^{236} \#$ and $\mathrm{Cf}^{252 *}$ fission neutron spectra. $(17,16)$ Quantitatively the calculated distributions were too energetic. The calculations did predict a $21 \%$ increase in the average fission neutron energy of $\mathrm{Cf}^{252 *}$ as compared to $\mathrm{U}^{236} \#$ in excellent agreement with the results of this experiment.

A much simpler approach was taken by the authors $(13,18,15)$ using a statistical model of the excited fragments. Spectra calculated using fragment temperatures of 0.8 and $1.0 \mathrm{Mev}$ for $\mathrm{U}^{236} \#$ and $\mathrm{Cf}^{252 *}$ fission respectively gave remarkably good agreement with experiment.

\section{PROMPT GAMMA RAYS ACCOMPANYING THE FISSION OF Cf $^{252 *}$}

A knowledge of the prompt $\left(<10^{-9} \mathrm{sec}\right)$ fission gamma ray spectrum is essential to the design of reactors and radiation shields. In addition the energy released in the form of quanta is important to the understanding of fission. Recent studies of the gamma rays emitted in the fission of $U^{236} \#$ are in disagreement with earlier experiments and with theory. $(19,20,16)$ It was thus decided to examine the prompt fission gamma ray spectrum of $\mathrm{Cf}^{252 *}$. The spontaneous nature of this process made possible a considerable reduction 
in the background associated with previous experiments. The measurement of a continuous gamma ray spectrum was difficult due to the lack of a detection system which gave a one-to-one correspondence between gamma ray energy and a measurable parameter. In this experiment the requirement of simultaneity between the gamma ray emission and fission was a further complication. The double crystal "Compton" spectrometer shown in Fig. 3 gave a unique spectral response over much of the energy range of interest.(21) Simultaneity between the fission event and the gamma ray emission was assured by the use of fast detectors and high speed coincidence techniques (resolving times $\sim 3 \times 10^{-9} \mathrm{sec}$ ). The experimental arrangement was such that there was no significant response to fast fission neutrons.

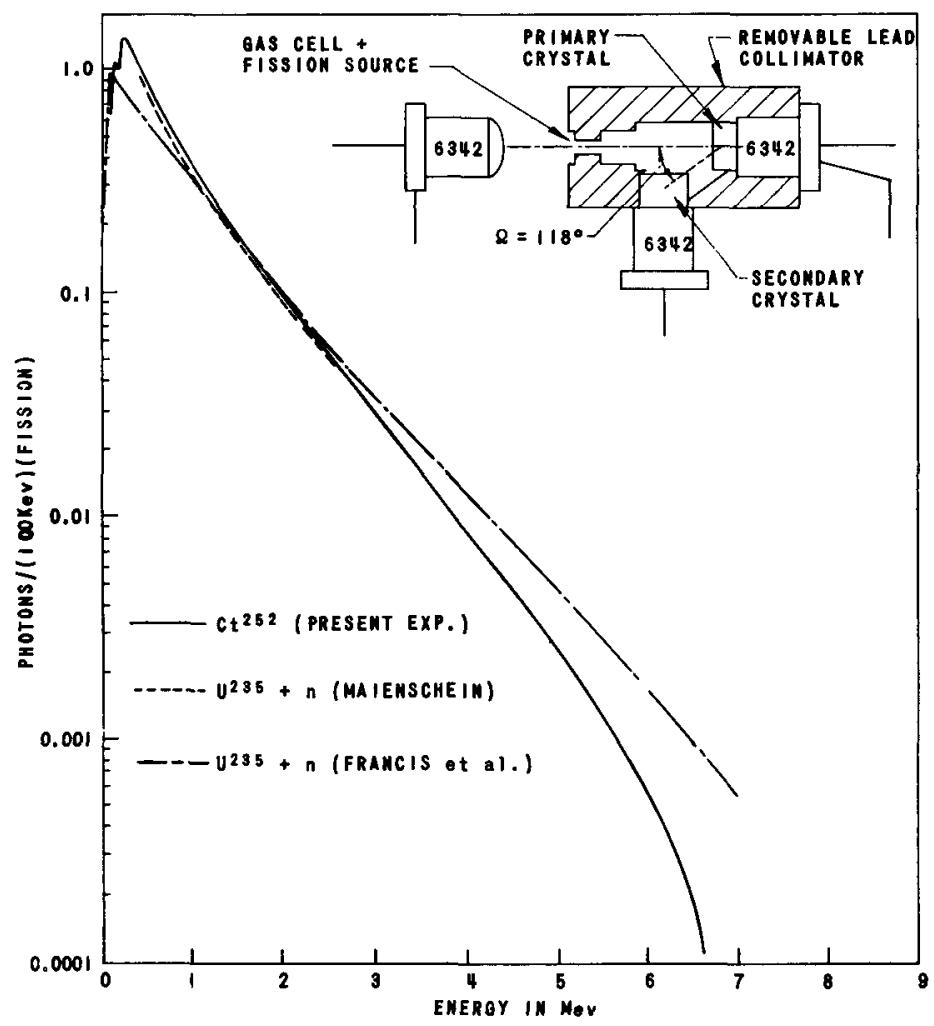

Fig. 3

The experimentally measured $\mathrm{Cf}^{252}$ prompt fiesion gamma ray spectrum compared with that of $U^{235}$. The equipment used in making the $\mathrm{Cf}^{252}$ measurements is shown in the upper portion of the figure.

The distribution of primary detector pulse heights in coincidence with a fission and a Compton scattered quanta were recorded on a multichannel analyzer. The gamma ray energy spectrum shown in Fig. 3 was obtained from this distribution. The gamma ray detection efficiency of the apparatus, thus the normalization of the spectrum, was measured using standard gamma sources.(22) Qualitatively it was evident that the prompt fission gamma ray spectrum of $\mathrm{Cf}^{252 *}$ was, above $0.5 \mathrm{Mev}$, a monotonically decreasing function of the energy.

The figure also shows that the recent measurements of the $U^{236} \#(19,23)$ fission gamma ray spectra are similar to the results of this experiment. 
Table III gives a numerical comparison of the number and energies of the quanta emitted in the fission of $\mathrm{U}^{236 \#}$ and $\mathrm{Cf}^{252 *}$. The results of this experiment indicate that the recent $\mathrm{U}^{236} \#$ gamma ray measurements are correct and that the former values and the theoretical estimates(16) are in error.

Table III

CHARACTERISTICS OF PROMPT PHOTONS FROM FISSION

\begin{tabular}{|c|c|c|c|c|c|}
\hline $\begin{array}{l}\text { Fissioning } \\
\text { Is otope }\end{array}$ & $\begin{array}{c}\text { Total } \\
\text { Photons } \\
\text { Fission }\end{array}$ & $\begin{array}{c}\text { Photons/ } \\
\text { Fission } \\
(0.5- \\
2.3 \mathrm{Mev})\end{array}$ & $\begin{array}{c}\text { Energy } \\
\text { Loss in } \\
\text { Photons } \\
\text { Fission } \\
(0.5- \\
2.3 \mathrm{Mev})\end{array}$ & $\begin{array}{c}\text { Total Energy } \\
\text { Loss in } \\
\text { Photons }\end{array}$ & Reference \\
\hline$C f^{252}$ & 10.3 & 5.0 & 5.2 & 8.2 Mev & $\begin{array}{l}\text { Present } \\
\text { Work }\end{array}$ \\
\hline $\mathrm{U}^{235}+\mathrm{n}$ & - & 5.0 & 5.1 & 8.0 Extrapolated & $\mathbf{a}$ \\
\hline $\mathrm{U}^{235}+\mathrm{n}$ & 7.5 & - & - & 7.46 & $\mathbf{b}$ \\
\hline
\end{tabular}

$a=$ see reference $23 \quad b=$ see reference 19

In the course of this experiment a search was made for very short lived delayed neutron and gamma ray emission. It was found that in the time interval 3-15 m $\mu \mathrm{s}$ after fission neither emanation was present in more than $5 \%$ yield per fission. The result was not unexpected since beta decay systematics precluded any delayed neutron precursors in this time interval and very short lived isomers were not expected in the mass region corresponding to high $\mathrm{Cf}^{252 *}$ yields.

\section{DELAYED NEUTRONS FROM THE SPONT ANEOUS FISSION OF $\mathrm{Cf}^{252}$}

Very soon after the discovery of the fission process the emission of a small number of neutrons delayed in the order of a second from the moment of fission was recognized.(24) This delayed neutron emission was attributed to fission fragments left in highly excited states after one or more beta decay processes. This precursor hypothesis for delayed neutron emission was generally verified by experiment. $(25,26)$ Unfortunately, the choice of precursors is not always unique. The fission mass yields of $U^{234} \#, U^{236 \#}$ and $\mathrm{Pu}^{240 \#}$ do not differ by large enough amounts to drastically effect the choice of delayed neutron precursors. However, in the fission of $\mathrm{Cf}^{252 *}$ the region of large light fragment yields occurs at appreciably higher mass 
numbers than in $\mathrm{U}^{236} \#$. Thus a comparison of the $\mathrm{Cf}^{252 *}$ delayed neutron and mass yields with those of other fissionable isotopes is a severe test of many possible precursor assignments. For this reason an experimental study of the delayed neutron yield of $\mathrm{Cf}^{252 *}$ was undertaken.

Most experimental studies of delayed fission neutron emission consist of briefly exposing a fissionable sample to neutrons and then transferring it to a neutron detection system where the delayed neutron activity is determined as a function of time after fission. A few investigations have consisted of a chemical separation of a particular fission fragment followed by a measurement of its delayed neutron activity.(27) This experiment belongs to the former category. The experimental arrangement is shown in Fig. 4.

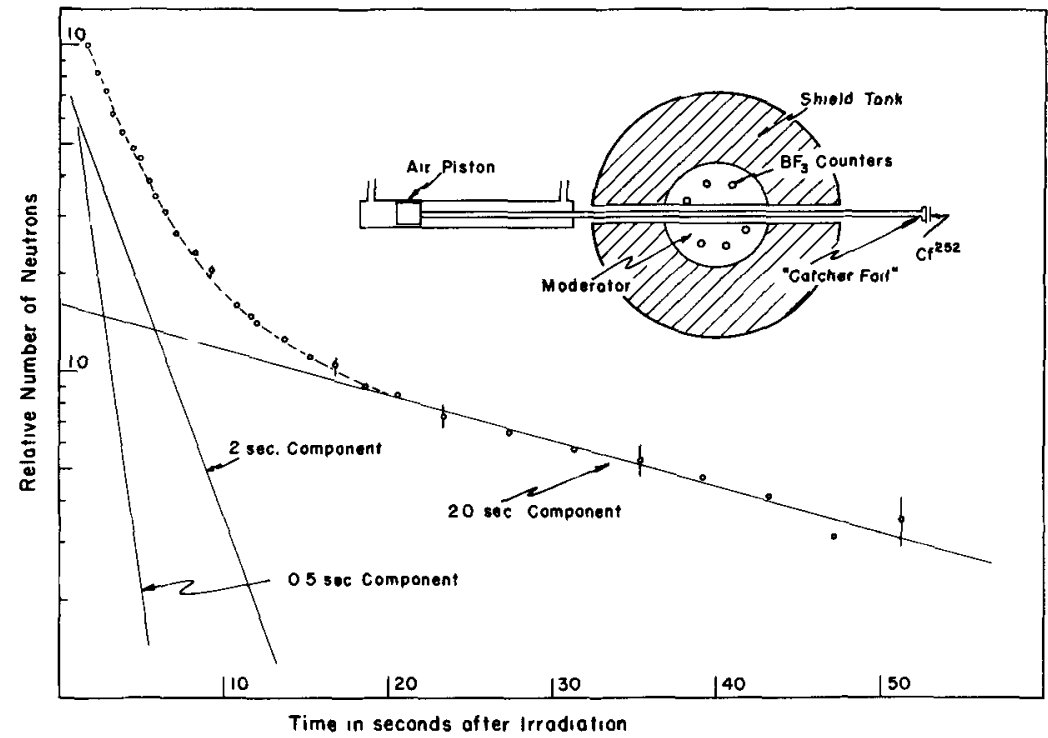

Fig. 4

A typical experimentally measured distribution of the delayed neutrons from $\mathrm{Cf}^{252}$ fission. This particular measurement was obtained with a $6 \mathrm{sec}$ irradiation period. The experimental arrangement is also shown.

A battery of $\mathrm{BF}_{3}$ counters is contained within a moderating medium which in turn is placed within a large shielding rank of borated water. A pneumatic shuttle is arranged to slide in and out of the counter and shield assembly at a preset cyclic rate. At the exterior limit of its travel this shuttle places a foil $0.5 \mathrm{~mm}$ from a sample of $\mathrm{Cf}^{252 *}\left(3.8 \times 10^{6} \mathrm{fissions} / \mathrm{min}\right)$. This foil catches the fragments leaving the $\mathrm{Cf}^{252 *}$ sample. After a "catching period" the foil is rapidly transferred to the center of the counting assembly. The neutron emission rate of the fragments is then determined as a function of time after irradiation. A typical experimentally obtained distribution of delayed neutrons from the fission of $\mathrm{Cf}^{252 *}$ is shown in Fig. 4.

Accepting the precursor hypothesis and assuming that only one beta decay transition precedes neutron emission, the distribution in time of the delayed fission neutron activity is given by:

$$
N(t)=\sum_{i=1}^{n} A_{i} b^{-b_{i} t}
$$


where $N(t)$ is the number of neutrons emitted per unit time, $A_{i}$ is the relative yield of the $i^{\text {th }}$ group, $b_{i}$ is the decay constant of the $i_{\text {th }}$ group, and $n$ is the total number of precursors. The parameters $n, A_{i}$, and $b_{i}$ in the above expression were adjusted by the method of least squares to give the best fit to the experimental data. This procedure showed that the fission of $\mathrm{Cf}^{252} *$ yields primarily three delayed neutron groups whose half lives and relative abundances are given in Table IV. The experimental technique would not be sensitive to a period whose half life was less than 0.3 second. The absolute yields given in the table were obtained from the fitting procedure, utilizing the experimentally determined values of the source strength and counting efficiency. For comparison, Table IV includes the delayed neutron yields of the thermal neutron induced fission of $\mathrm{U}^{236} \#$ as measured by Keepin.(26)

Table IV

Cf ${ }^{252 *}$ DELAYED FISSION NEUTRON YIELDS

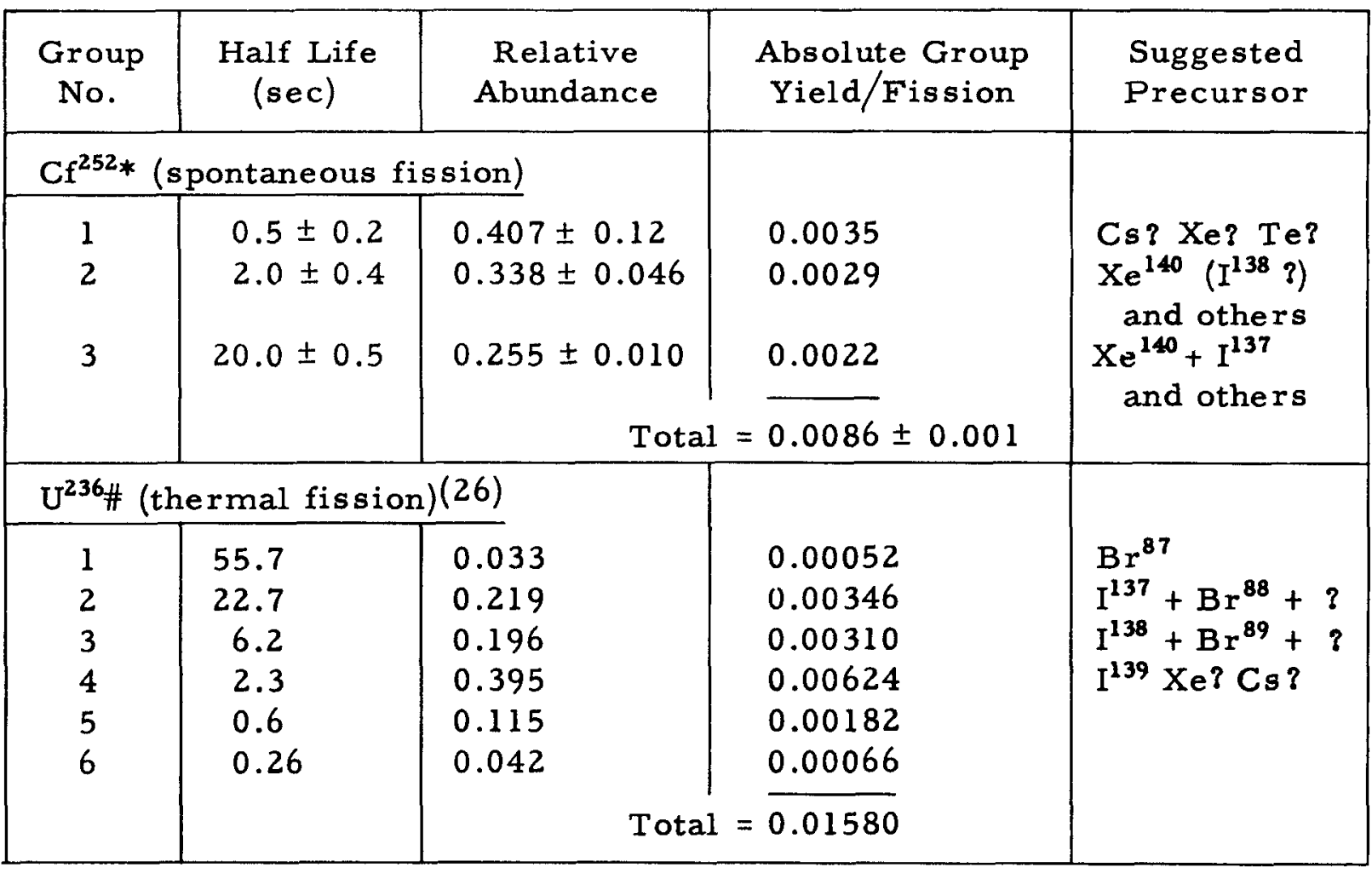

Suggested $U^{236 \# ~ d e l a y e d ~ n e u t r o n ~ p r e c u r s o r s ~ a r e ~ a l s o ~ g i v e n . ~ T h e s e ~ a s s i g n-~}$ ments are based on positive chemical determinations $(27,28)$ correlations of delayed neutron and fission mass yields of $\mathrm{U}^{236} \#, \mathrm{U}^{234} \#, \mathrm{U}^{239} \#$ and $\mathrm{Pu}^{240} \#$ fission (26) and on beta decay systematics.(28) The fission product yields of $\mathrm{Cf}^{252 *}$ in the mass region 85-95 are relatively much smaller than those of $\mathrm{U}^{236} \#$. Thus few, if any, $\mathrm{Cf}^{252 *}$ delayed neutrons should originate in precursors whose masses are in the region of large light fragment yields in $\mathrm{U}^{236 \#}$ 
fission. Therefore arsenic and bromine precursors should not result from $\mathrm{Cf}^{252 *}$ fission. This is in agreement with the experiment, which does not detect a measurable $55 \mathrm{sec}\left(\mathrm{Br}^{87}\right)$ delayed neutron period in $\mathrm{Cf}^{252 *}$ fission. Furthermore there is not a measurable $6 \mathrm{sec}$ delayed neutron group present in $\mathrm{Cf}^{252 *}$ indicating that the $\mathrm{Br}^{89}$ precursor is probably the dominant contributor to that period in the $\mathrm{U}^{236} \#$ fission. This is consistent with the relative yield of this period in $\mathrm{Pu}^{240} \#$ fission and is not in disagreement with the chemical identification of a $6 \mathrm{sec}^{139}$ precursor of unknown intensity. The $22 \mathrm{sec}$ $\mathrm{U}^{236} \#$ period is now attributed to a combination of $\mathrm{Br}^{88}$ and $\mathrm{I}^{137} .(27)$ It is difficult to interpret the present experimentally determined $20 \mathrm{sec}$ period as being due to the $24 \mathrm{sec} \mathrm{I}^{137}$. Certainly, if present, an $\mathrm{I}^{137}$ period must be mixed with a new precursor of about $15 \mathrm{sec}$ half life, perhaps $\mathrm{Xe}^{140}$. The nature of the precursor hypothesis, and known beta decay systematics, do not exclude the possibility that delayed fission neutron emission involves a large number of precursors not known at this time. While the results of this experiment definitely support the assignment of bromine delayed neutron precursors in $\mathrm{U}^{236} \#$ fission they do not clarify the current picture of heavy delayed neutron precursors. The argument for a more complex precursor sequence is substantiated by the relatively high total delayed neutron yield in $\mathrm{Cf}^{252}$ fission, far larger than is consistent with present known heavy fragment precursors.

\section{CONCLUSION}

The experiments reported in this paper extend the knowledge of the fission process over a considerably wider range of nuclei. This increased information should provide a firmer basis upon which to construct a theoretical understanding of fission and should provide a wider testing ground for new theoretical concepts. Some of the experimental results are of direct usefulness in applications of the fission process to the benefit of mankind.

\section{REFERENCES}

1. Bunemann, O., et al., Can. J. Research, 27:191 (1949).

2. Bentley, et al., Proceedings of the International Conference on the Peaceful Uses of Atomic Energy, Geneva, 1955 (United Nations, New York 1956), Paper P/809.

3. Stein, W., Phys. Rev., 108:94 (1957).

4. Milton, J. and Fraser, J., Chalk River, Report PD-288, 1958, Unpublished. 
5. Cohen, B. L., et al., Phys. Rev., 104:1046 (1956).

6. Fong, P., Phys. Rev., 102:434 (1956).

7. Cameron, A., Private Communication.

8. Perlman, I. and Asaro, F., Alpha Radioactivity, Annual Review of Nuclear Science, Vol. 4 (1954), Annual Reviews, Inc., Stanford, California.

9. Cranberg, et al., Phys. Rev., 103:662 (1956).

10. Nereson, N., Phys. Rev., 88:823 (1952).

11. See Paper $P / 1098$.

12. Cranberg, L., Proceedings of the International Conference on the Peaceful Uses of Atomic Energy, Geneva, 1955 (United Nations, New York 1956), Paper P/577, Vol. 4.

13. Fraser, J. S., Phys. Rev., 88:536 (1952).

14. Watt, B., Phys. Rev., 87:1037 (1952).

15. Blatt, J. and Weisskopf, V., Theoretical Nuclear Physics, John Wiley and Sons, New York (1952).

16. Leachman, R. B., Proceedings of the International Conference on the Peaceful Uses of Atomic Energy, Geneva, 1955 (United Nations, New York 1956), Paper P/592, Vol. 2.

17. Leachman, R. and Kazek, C., Phys. Rev., 105:1511 (1957).

18. Feld, et al., U. S. Atomic Energy Commission Document, NYO-636, Unpublished.

19. Francis, J. and Gamble, R., Oak Ridge National Laboratory, Report, ORNL-1879, Unpublished

20. Kinsey, et al., Can. J. Research, 26:79 (1949).

21. Hofstadter, R. and McIntyre, J., Phys. Rev., 78:134 (1950).

22. Obtained from the National Bureau of Standards, Washington, D.C.

23. Maienschein, et al., Oak Ridge National Laboratory Report, ORNL-1142, Unpublished. 
24. Bohr, N. and Wheeler, J., Phys. Rev., 56:426 (1939).

25. Këèpin, G. R., Los Alamos Scientific Laboratory Document, LA-1970, 1955, Unpublished.

26. Keepin, et al., Phys. Rev., 107:1047 (1957).

27. Perlow, G. and Stehney, A., Phys. Rev., 107:776 (1957).

28. Keepin, G. R., Private Communication. 